\title{
Pickering Stabilized Miniemulsion Polymerization: Preparation of Clay Armored Latexes
}

\author{
Séverine Cauvin, Patrick J. Colver, and Stefan A. F. Bon* \\ Department of Chemistry, University of Warwick, Coventry CV4 7AL, UK.
}

S.Bon@warwick.ac.uk, Tel: +44 (0)2476 574009, Web: www.stefanbon.com

Supplementary information

PAGE 1: $\quad$ Detailed experimental procedures

PAGE 2: $\quad$-SEM image of Laponite RD armored polystyrene latex. Scale-bar indicates $1.0 \mu \mathrm{m}$. 


\section{Experimental:}

\section{Materials:}

Laponite RD, with ideal chemical formula $\left[\mathrm{Si}_{8}\left(\mathrm{Mg}_{5.45} \mathrm{Li}_{0.4}\right) \mathrm{O}_{20}(\mathrm{OH})_{4}\right] \mathrm{Na}_{0.7}$, was kindly donated by Rockwood additives Ltd. dimethyl-2,2-azobis(isobutyrate) (V-601) and 2,2'-azobis(2-amidino propane) dihydrochloride (V-50) were donated by Wako Chemicals. All other Chemicals were of analytical grade and obtained from Aldrich. Styrene was passed over a short Column of basic alumina to remove the inhibitor prior to use.

\section{Equipment:}

$\mathrm{pH}$ measurements were performed on a Knick $\mathrm{pH}$ meter 765 . Sonication was performed using a Branson digital 450W sonifier. Dynamic Light Scattering measurements were performed on a Malvern instruments, zetasizer $3000 \mathrm{HSA}$, using a $0.1 \mathrm{M} \mathrm{NaCl}$ solution at $\mathrm{pH} 10$ as solvent. FE-SEM measurements were performed on a ZEISS supra 55VP FEGSEM.

\section{Method for pickering stabilized miniemulsion polymerization:}

$\mathrm{NaCl}(0.572 \mathrm{~g})$ and Laponite $\mathrm{RD}$ clay disks $(0.473 \mathrm{~g})$ were added to deoxygenated distilled water $(100 \mathrm{~mL})$. While on ice and being stirring, the mixture was sonicated using a Branson $450 \mathrm{~W}$ sonifier at 70\% amplitude for 6 mins, 30secs in $1 \mathrm{~min}$ intervals with a 30 second rest. dimethyl-2,2azobis(isobutyrate) (V-601: $0.12 \mathrm{~g})$ and hexadecane (0.43 g) were mixed with styrene (5.0082g, 50eq), after which this was added to the clay dispersion. The mixture was then sonicated again using the same procedure, keeping the temperature below $40^{\circ} \mathrm{C}$ to prevent early polymerization. Next the miniemulsion was purged with Nitrogen gas for 20 minutes, after which it was polymerized at $65{ }^{\circ} \mathrm{C}$ overnight. 


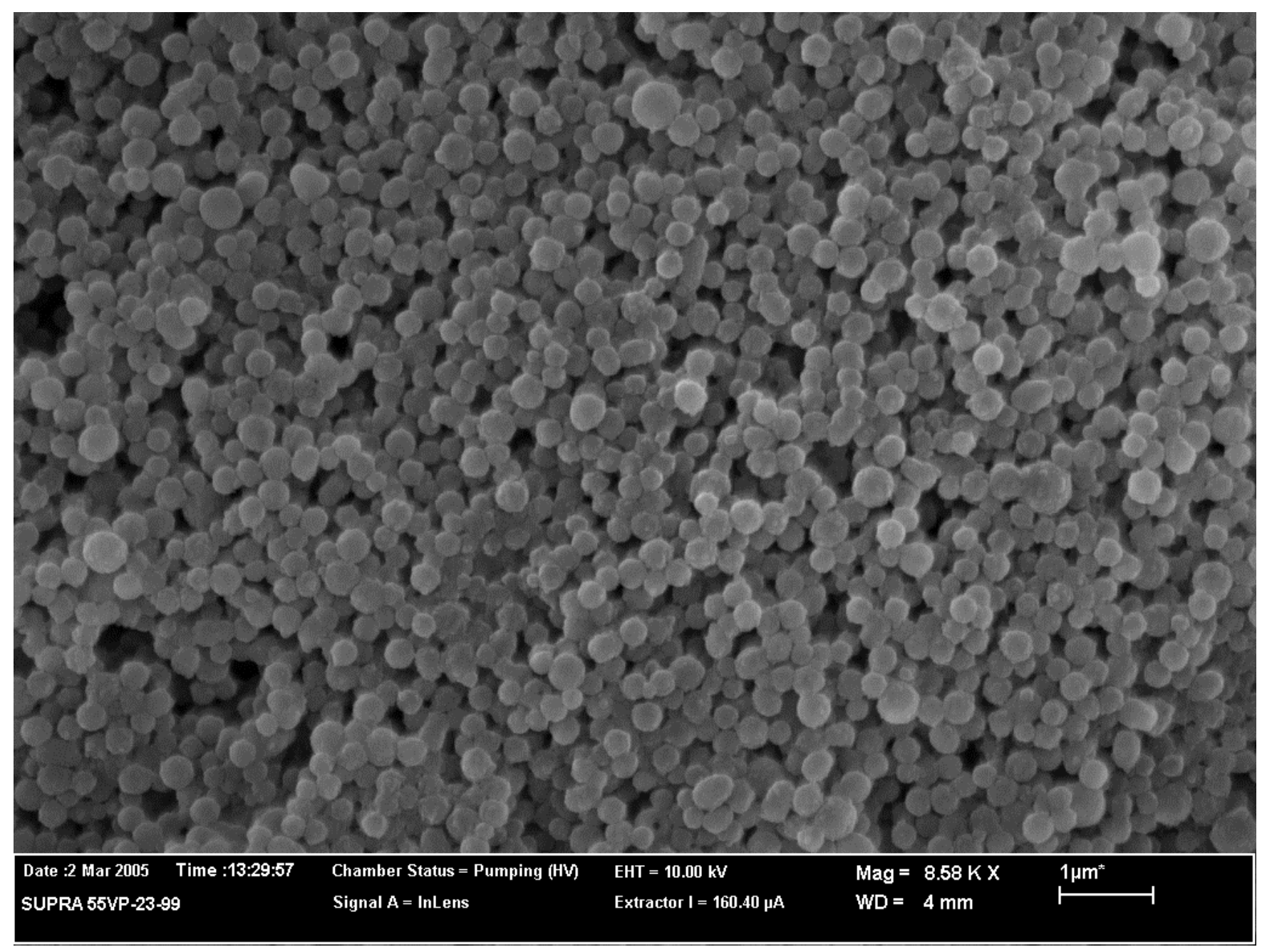

